\title{
Numerical Analysis of Diversion Flow Stream Around of Bend Canal Wall in Dez River Intake
}

\author{
Ahadiyan J. ${ }^{1}$, Haji Ali Gol S. ${ }^{2}$ \\ ${ }^{1}$ Hydraulic Structure Water Science Engineering Faculty of Shahid Chamran University (SCU), Ahwaz, Iran \\ ${ }^{2}$ Hydraulic Structure in Sharab Consulting Engineers, Ahwaz, Iran
}

Email address:

Ja_ahadiyan@yahoo.com (Ahadiyan J.),Hj_sd@yahoo.com (Haji A. G. S.)

\section{To cite this article:}

Ahadiyan J., Haji Ali Gol S. Numerical Analysis of Diversion Flow Stream Around of Bend Canal Wall in Dez River Intake. American Journal of Software Engineering and Applications. Vol. 5, No. 3, 2016, pp. 15-20. doi: 10.11648/j.ajsea.20160503.11

Received: July 17, 2014; Accepted: February 16, 2015; Published: April 26, 2016

\begin{abstract}
Investigation of flow pattern through intake structures is one of important issue which should be considered under design procedure. In this study, simulation of flow regime of side way intake structure with $\mathrm{T}$ shape-Intake which is feed from Dez River has been done. Because of different problem in Sabili intake of Dez River, the process of utilizing curved cancel is studied scientifically. To achieve the purpose, velocity distribution profile accompany turbulent Energy at inlet of structure have been studied. As a result, energy turbulence has been increased gradually to 60 percent and energy disputing from beginning to end a path of river has increased 31 percent. But maximum velocity at situation (without intake structure) decreased from $61 \%$ to $42 \%$ subsequently.
\end{abstract}

Keywords: Curved Canal, T-Shape, Water Intake Structure, Flow Algorithm, Flow - 3D

\section{Introduction}

Generally, water Intake from river is very complicated operation and usually has been done in two categories, (1) pumping method (2) gravity method. Although some standards, according to the studies, have been achieved, many pump station and turnout structures have faced to side erosion and many of them have sedimentation problem. In other words, inlet path always are attacked with sediment and erosion. It is correct that human tried had to use water from river, but many studied remain and one complete resource didn't gathered carefully, more over shape of specific hydraulic structure is function of many factors such as, project location, directing water from river and many related equations and formula. So, many sciences are used such as soil mechanic, hydrology, hydraulic and etc as base. The pump station of Sabili is located at upstream of Dez diversion dam at Khuzestan province, in order to water conveying to land of Sabili region. This intake designed to convey water from Dez River to pump station. This conveying path (channel) is compound with the side wall slope 2:1 and the length is about 385 meter, designed bed level of convey channel is 126 , and bed level of river is about 123 to 124 .The studies of flow regime at beginning of inlet in order to determine hydraulic properties at cross section of turn out channel is aim of this research: Safarzade et al (2002) studied three dimension of concept of turbulent flow at side water intakes, with using two phases model and they concluded that validation had acceptable convergence and bed lead could been studied scientifically. Vahid et al (2010) investigated water profile at new method of water intake with using bottom intake method and concluded that uniformity of flow stream at low discharge is more than profile uniformity at high range of flow Discharge. Moazen and shafaee (2008), attempt to study sediment dredging efficiency through vortex tube and they finally found out, Froud number increasing has great effect on vortex tube and make it decreased enormously. Sajadi and Shafai (2009), tried to evaluate sediment trap basin models and they deducted that imperial model of stilling basin, because of lack of knowledge of flow algorithm here very high rate of mistakes. Keshavarz et al (2009), tried to simulate 3 Dimension of algorithm around vertical and angled spur dike with different boundary condition and according to the results, modeling with free surface and assumption of rigid Doer has been done. Using time (rigid- lid) has great effect on. Calculation and decrease rapid process of program, but unfortunately the results from model is not so logical and has a 
lot mistakes. Shamloo et al (2010) tried to study effects of Geometrical and hydraulic Dimension on flow separation zone; through side wall water Intakes with using fluent software, they finally found out choosing suitable turbulent model. Suit to flow Condition is more important; therefore, investigation the effect different hydraulic parameter. Such as, Geometric and hydraulic like width of Directed channel through main channel, angle of diversion, Froude number of inlet flow, and Discharge distribution show that, at all condition, when flow rate Increase then dimension of flow separation zone through diverted canal is going to be smaller. In constant distribution discharge using by two gate outlet, the dimension of separation zone is independent of inlet flow condition. In this regards, this case is dependent of bottom width of either canal or deflection angle. Godsion et al (2010) studied effect of canal curve on bed scouring depth and concluded that at almost experiments, position of maximum depth of scouring are related to discharge increase and Froude number and after a while, will be transferred to the downstream of channel. Maximum scouring depth is always created at about 60-90 degree location of curve start point and must of them are located at 80-90 degree location. Pirestasni et al, (2008) investigated flow pattern on lateral intake in the curved channel by using physical model. They showed that the variation of velocity profiles and water surface have a significant influence of diversion discharges. In addition they concluded that increasing longitudinal velocity in inlet of intake the water surface increases and on the base of energy equation the lateral discharges increases. Neishaboori et al, (2004) evaluated of the 3D numerical model on lateral intake and showed that the k- $\varepsilon$ model have a good accuracy and the results satisfactory compliance with results of physical models.

\section{Methods and Materials}

As it is mentioned before the introduction proposes of this study is simulation and investigation of flow algorithm at bend shape canal of sabili water intake structure. So for achieving this purpose flow-3D has been used. This model is multi-dimensional model for simulation of complicated hydraulic problem. The method of solving the equations is based on finite volume method and it included of continuity and momentum equations and diffusion has numerical solution. The continuity Equation is from derived from moss equilibrium for one fluid cell of below:

$v_{f} \frac{\partial p}{\partial t}+\frac{\partial}{\partial X}(P . U . A x)+R(P l e A g)+\frac{\partial}{\partial Z}(p v \cdot A Z)+\varepsilon \frac{P \cdot U A_{X}}{X}=R_{D I F}+R_{S O R}$

In which: Vf is portion of open flow volume at $\mathrm{x}$ direction $\mathrm{Ax}, \mathrm{Ay}, \mathrm{AZ}$ are one sections of open flow volume at $\mathrm{x}, \mathrm{y}, \mathrm{z}$ direction. At this equation, $\mathrm{R}$, are operational Coefficients. For Cartesian coordinate system $\mathrm{R}$ parameter is equal to 1 and is equal to zero. First term at right side of (2) equation is turbulent diffusion term and calculated of below:

$$
R_{D I F}=\frac{\partial}{\partial X}\left(V_{P} A_{X} \frac{\partial \rho}{\partial X}\right)+R \frac{\partial}{\partial Y}\left(V_{P} A_{Y} R \frac{\partial \rho}{\partial Y}\right)+\frac{\partial}{\partial Z}\left(V_{P} A_{Z} \frac{\partial \rho}{\partial Z}\right)+\varepsilon \frac{\rho V_{P} A_{X}}{X}
$$

Where in this equation $v_{\rho}$ is equal to $c_{\rho} \mu / \rho$ and $\mu$ is diffusion equation coefficient and $c_{\rho}$ is coefficient which is related to turbulent Schmitt member. This term is mass distribution and related to validate turbulent combination process and is only usable for non-uniformity practical fluid. the last term, at equation (2) is related to source at under condition of 2 phases fluid has been used. Navier- stockes equation with velocity component $(\mathrm{u}, \mathrm{v}, \mathrm{w})$, are from other equation of flow

Analysis which these has been showed of below:

$$
\begin{aligned}
& \frac{\partial U}{\partial t}+\frac{1}{V_{f}}\left[u A_{x} \frac{\partial U}{\partial X}+v A_{y} \frac{\partial U}{\partial Y}+w A_{z} \frac{\partial U}{\partial z}\right]=-\frac{1}{\rho} \frac{\partial \rho}{\partial x}+G_{x}+f_{x} \\
& \frac{\partial v}{\partial t}+\frac{1}{V_{f}}\left[u A_{x} \frac{\partial v}{\partial X}+v A_{y} \frac{\partial v}{\partial y}+w A_{z} \frac{\partial v}{\partial z}\right]=-\frac{1}{\rho} \frac{\partial \rho}{\partial y}+G_{y}+f_{y} \\
& \frac{\partial w}{\partial t}+\frac{1}{V_{f}}\left[u A_{x} \frac{\partial w}{\partial X}+v A_{y} \frac{\partial w}{\partial y}+w A_{z} \frac{\partial w}{\partial z}\right]=-\frac{1}{\rho} \frac{\partial \rho}{\partial z}+G_{z}+f_{z}
\end{aligned}
$$

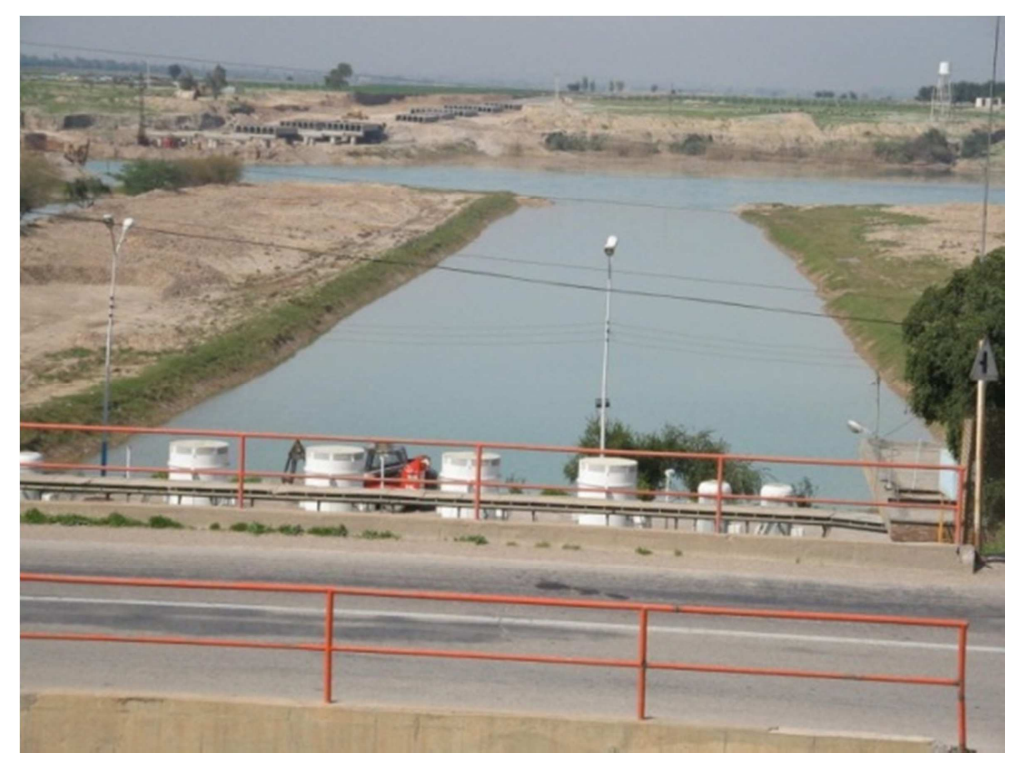

Fig. 1. Schematic picture of Sabili water intake structure. 


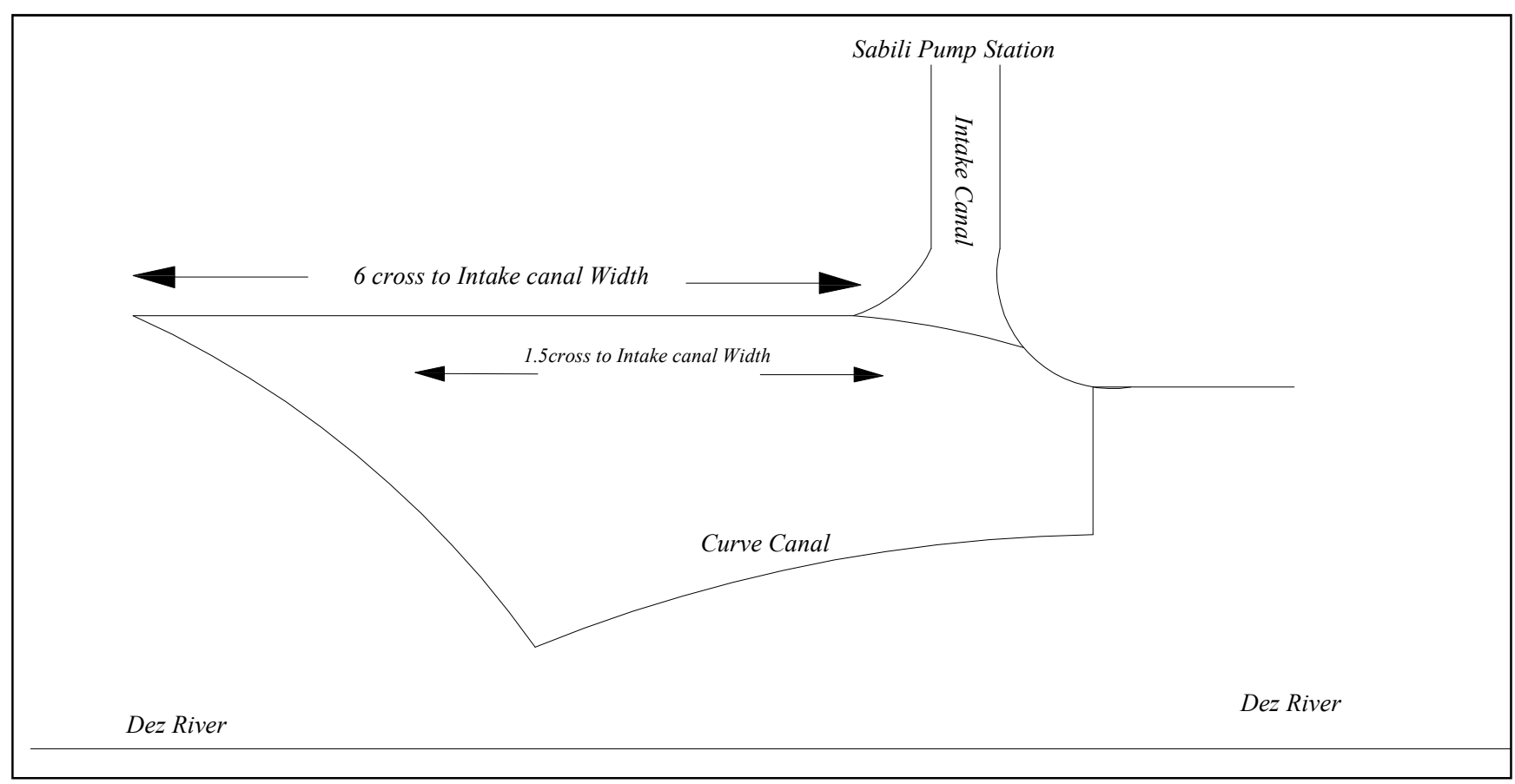

Fig. 2. Schematic curved canal of Sabili intake.

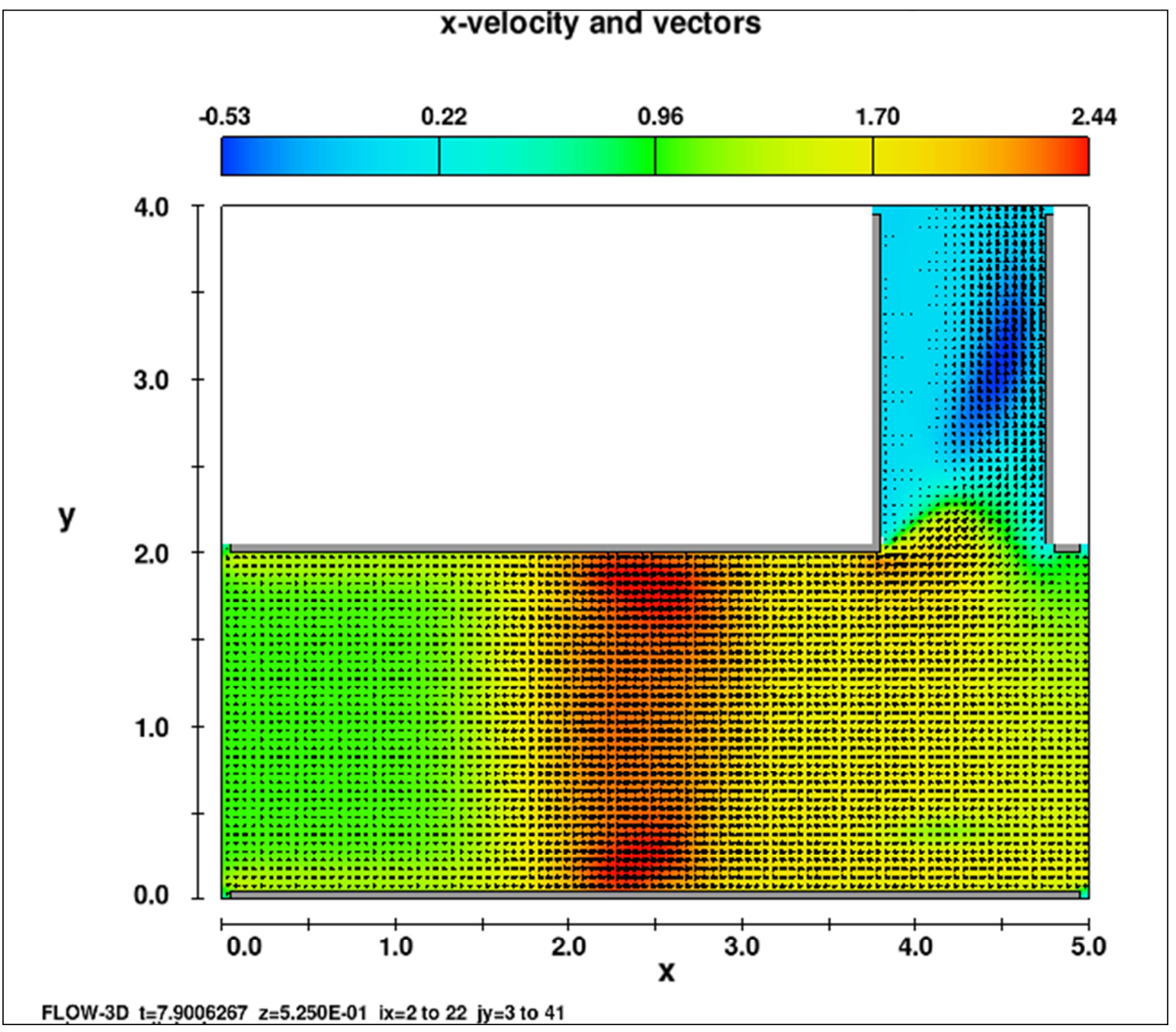

Fig. 3. Flow algorithm at situation without curved canal. 
At these equations, $\left(G_{X}, G_{Y}\right.$, and $\left.G_{z}\right)$, mass acceleration And $\left(f_{x}, f_{y}, f_{y}\right)$ are viscosity acceleration : so, in this research, water intake structure of sabili had been simulated. Figure 1 shows the pumping station and water intake of sabili.

Accordance of Figure 1 and as mentioned before, Sabili intake has a shape in form of $\mathrm{T}$ shape and its water is supplying form Dez River. Now, this structure has too many problems, such as problem of water in taking due to sedimentation, so the rehabilitation is necessary. In the research simulation has been followed at two conditions: first $\mathrm{T}$ shape canal has been modeled without bend curve canal and second, simulation has been done with curved canal. Schematic curved canal has been shown as follow:

\section{Results and Discussions}

In the study, effect of bend canal on flow algorithm at Sabili pump station has been studied. To achieve of these purposes the models was run on 2 cases: one without any curved canal and two with a curved canal. Figure 3 shows the results of without any curved canal

As observed a figure 3 , in location of canal intake, some points through in takes have minimum velocity which cause to sediment deposition through connected canal. Thus, to more accurately investigation, velocity depth profiles through path line flow for the more near points to intake has been plotted. The results of this subject were shown at figure besides; average of hydraulic parameters such as velocity, rate of turbulent energy and turbulent dissipating through inlet of intake has been illustrated at table 1 .

Table 1. Hydraulic properties of flow in inlet canal (without curved canal).

\begin{tabular}{llll}
\hline $\mathbf{X}$ & $\mathbf{U}_{\text {ave }}$ & tke & dtke \\
\hline 3.825 & 1.961101 & 0.010738 & 0.01511 \\
3.925 & 1.931423 & 0.011474 & 0.015676 \\
4.025 & 1.88628 & 0.011967 & 0.015685 \\
4.125 & 1.805836 & 0.012202 & 0.015182 \\
4.225 & 1.67497 & 0.012274 & 0.014411 \\
4.325 & 1.475544 & 0.014463 & 0.015948 \\
4.425 & 1.168398 & 0.015949 & 0.017628 \\
4.525 & 0.928202 & 0.017109 & 0.018251 \\
4.625 & 0.740048 & 0.018304 & 0.017625 \\
4.725 & 0.606701 & 0.023044 & 0.020984 \\
4.825 & 0.689537 & 0.025023 & 0.022173 \\
\hline
\end{tabular}

Where in table 1: $x$ coordinate is longitudinal streamline of river, $U_{\text {ave }}$ is average velocity at each of $x$ point $(x=3 / 825$ is beginning point in intake canal at river Geometric data of flow-3D).

"tke" is turbulent energy, and "dtke" is average dissipating energy at local position. The turbulent energy consists of turbulent conveying equation at kinematical energy and fluctuated turbulent velocity which is of below:

$$
K_{T}=\frac{1}{2}\left(\overline{u^{\prime 2}}+\overline{v^{\prime 2}}+\overline{w^{\prime 2}}\right)
$$

At this equation: $u^{\prime}, v^{\prime}$ and $w^{\prime}$ are turbulent velocity fluctuations coefficients. A coefficient $1 / 2$ observed in this equation is closed based on kinematical energy from three directions with Cartesian axis. Moreover, it is necessary explained that energy dissipating was modeled with $\mathrm{k}-\varepsilon$ model for simulation. Figure 4 shows the velocity profiles at inlet point.

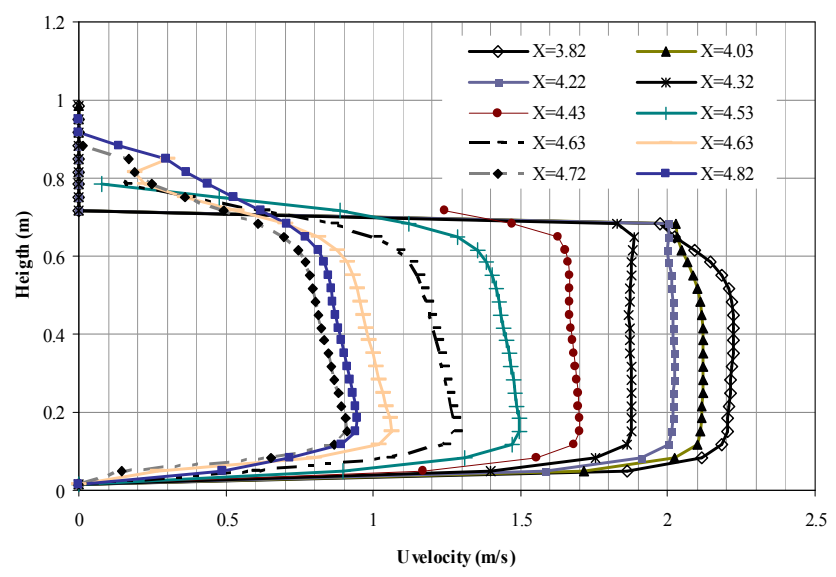

Fig. 4. The variation of velocity profiles at inlet beginning point.

On the base of Fig 4: these have been deducted that maximum velocity at entering point of intakes occurred. However, velocity decreased less than half at end point of canal. These variations of velocity is from $2.2 \mathrm{~m} / \mathrm{s}$ to 0.85 $\mathrm{m} / \mathrm{s}$ which may caused vortex velocity at beginning point of inlet. Therefore, energy dissipating has been occurred again. For quantities investigations show that the variation energy turbulence from start point of canal to end point decreased steadily approximately $60 \%$. While the value of turbulence energy dissipation increase in start path of river to end is about $31 \%$. Figure 5 shows velocity profile at start point of inlet. Moreover, table 2 shows average hydraulic parameter at inlet point of $\mathrm{T}$ shape intake structure.

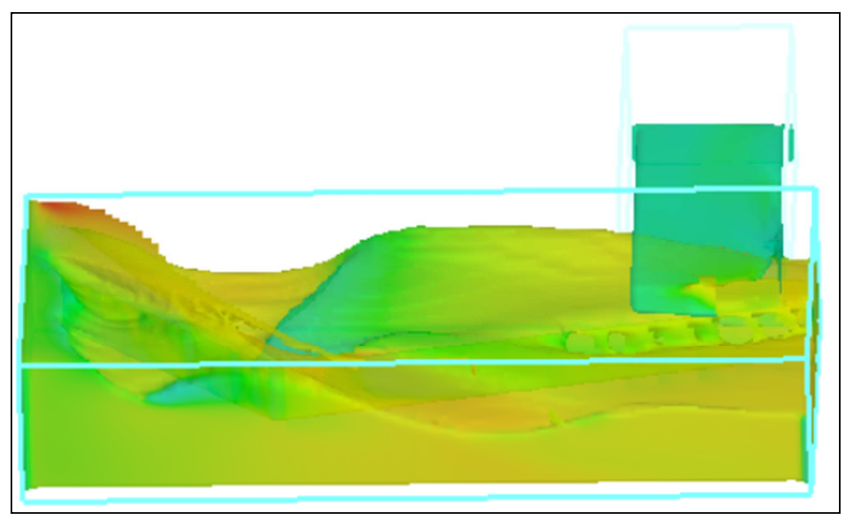

Fig. 5. Schematic view of model results at curved canal.

Figure 5 demonstrates model with curved canal which work as baffled at upstream of water intake structure. 
Table 2. Hydraulic characteristic at intake inlet point.

\begin{tabular}{llll}
\hline $\mathbf{X}$ & $\mathbf{U}_{\text {ave }}$ & tke & dtke \\
\hline 3.8250 & 0.0020 & 0.0015 & 0.0194 \\
3.9250 & 0.0313 & 0.0535 & 0.0535 \\
4.0250 & 0.0419 & 0.0860 & 0.5702 \\
4.1250 & 0.0344 & 0.0729 & 0.8784 \\
4.2250 & 0.0250 & 0.0496 & 1.0665 \\
4.3250 & 0.0194 & 0.0342 & 1.0849 \\
4.4250 & 0.0265 & 0.0411 & 0.8152 \\
4.5250 & 0.0320 & 0.0464 & 0.6099 \\
4.6250 & 0.0331 & 0.0427 & 0.3999 \\
4.7250 & 0.0071 & 0.0097 & 0.0915 \\
\hline
\end{tabular}

According to the table 2, turbulence energy is from inlet point at longitudinal profile is almost $85 \%$ increase and energy dissipation is increased to $75 \%$. At second situation, curved canal has been simulated. Figure 6 shows the velocity profile at inlet structure in instruct of river.

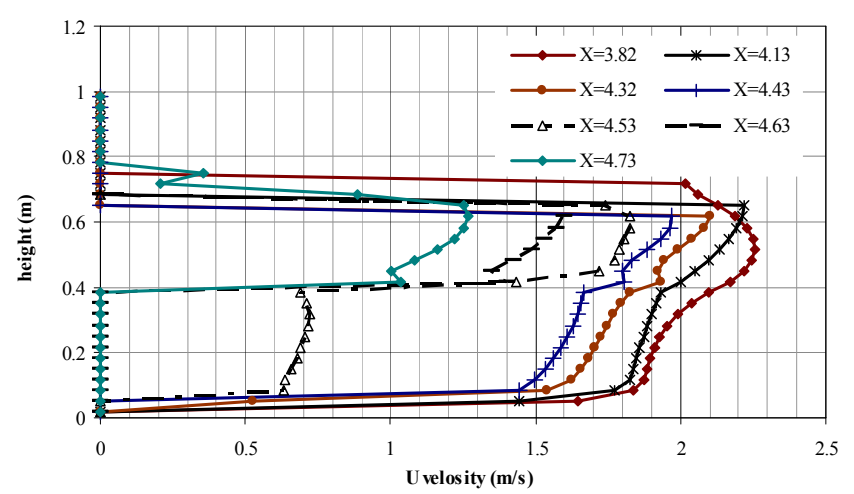

Fig. 6. The variation of velocity profile in the intake inlet (river).

As it is mentioned before, due to baffled structure of intake construction, flow velocity has been broken eventually. Generally, from inlet point to end, flow velocity at intakes is decreased from $2.35 \mathrm{~m} / \mathrm{s}$ to $1 / 3 \mathrm{~m} / \mathrm{s}$. In comparison, using curved canal, velocity gradient gradually decreased, subsequently vertex speed. Which influenced on sedimentation is decreased to as aspect of quantity maximum velocity gradient decreased from $61 \%$ to $42 \%$ (without using bend channel). According to this using bend channel at modifying flow algorithm is so effective vertex velocity of energy table 3: shows turbulent parameters and turbulent energy and average velocity at beginning point. Table 3 shows the flow characteristics with using bend channel through river at inlet point of intake.

Table 3. Hydraulic characteristic in the intake canal inlet with bend canal.

\begin{tabular}{llll}
\hline $\mathbf{X}$ & tke & dtke & Uave \\
\hline 3.8250 & 0.0386 & 0.0527 & 1.8620 \\
3.9250 & 0.0430 & 0.0636 & 1.8370 \\
4.0250 & 0.0460 & 0.0748 & 1.7647 \\
4.2250 & 0.0512 & 0.1120 & 1.6159 \\
4.2250 & 0.0436 & 0.0972 & 1.6515 \\
4.3250 & 0.0484 & 0.1162 & 1.5802 \\
4.4250 & 0.0612 & 0.4741 & 0.8137 \\
4.5250 & 0.0612 & 0.4741 & 0.8137 \\
4.6250 & 0.0330 & 0.1477 & 0.4538 \\
4.7250 & 0.0336 & 0.0833 & 0.4469 \\
4.7750 & 0.0506 & 0.1039 & 0.4568 \\
\hline
\end{tabular}

According to table 3 maximum velocity at inlet point of river is decreased from $1.86 \mathrm{~m} / \mathrm{s}$ to $0.45 \mathrm{~m} / \mathrm{s}$ in addition, variation of turbulent energy (if channel is exist) has been grow to $23 \%$ percentage. Although, if bend channel is not exist velocity changing has been increased to $60 \%$, as a result bend channel is so affection. Moreover, turbulent energy dissipating at existence of bend channel is about $50 \%$ but for none existing decrease of version flow potential is at condition which bend channel has been used.

\section{Conclusion}

According to this research the brief results as follow.

- If the bend channel is not used: velocity changing at inlet point to water inlet is fell down from $2.2 \mathrm{~m} / \mathrm{s}$ to $0.85 \mathrm{~m} / \mathrm{s}$ and may cause vortex velocity (eddy flow) through entrance bend channel has declined from $61 \%$ to $42 \%$.

- Turbulent energy changing: from beginning point to the end give up to $60 \%$ forint. But energy dissipating increased only $31 \%$.

- Turbulent energy at enterers point (at longitude direction) grows to $85 \%$ as well as turbulent energy dissipating (which is about $78 \%$ ).

- to sum up is bend channel has been used, maximum velocity is normally decreased from 1.86 to $0.45 \mathrm{~m} / \mathrm{s}$, beside turbulent energy of at (bend channel existence) is rocket to $23 \%$ and turbulent energy dissipating is changed up to $50 \%$.

\section{References}

[1] Vahid, koorosh., "Experimental consideration of water surface profiles formation in new method of intake by palmer intake with permeable conduit", the $8^{\text {th }}$ international conference of civiling Engineering, shiraz., Iran, (2009).

[2] Moazen, Iman., "Sediment efficiencies experimental of vortex pipe sedimentary in beginning of canals", National congress of Irrigation and Drainage networks management"., shahid chamran uni, (2005).

[3] Keshavarz, M. H., "3D numeral simulation of flow pattern around the vertically and transverse coast Epees with various boundary conditions", Iranian sea Engineering association, Sea engineering publication. $4^{\text {th }}$ year. No-8 (2008).

[4] Shamloo, hamid., "Experimental effects of hydraulic and Geometrical parameters on dimensions of Flow separation region with Fluent software"., surveying and caviling engineering publication. Technical college. P487-495, No 4,44 (2010).

[5] Pirestani, M. R, "Flow assimilation over the side intake in arch floodway with physical model", soil water magazine (Agricultural industries and sciences). 22 copies, No2 (2008).

[6] Salehi neyshaboori, Seid Aliakbar, "Numerical Modeling of 3D flow pattern in side intake", $1^{\text {st }}$ national congress of civil engineering, sharif industrial university. (2003).

[7] Barkdoll, B. D., "Sediment Control at Lateral Diversion", PhD dissertation, Civil and Environmental Engineering, University of Iowa, Iowa City, Iowa, 1997. 
[8] Shettar, A. S., and Murthy, K. K., "A Numerical Study of Division of Flow in Open Channels", J. Hydr. Res., V. 34, No. 5, 1996, pp. 651-675.

[9] Issa, R, I., and Oliveira, P. J., "Numerical Prediction of Phase Separation in Two-Phase Flow Through T-junctions", Comp. Fluids, V. 23, No. 2, 1994, pp. 347-372.

[10] Neary, V. S., Sotiropoulos, F., and Odgaard, A. J. ThreeDimensional Numerical Model of Lateral-Intake Inflows", J. HYDRAUL. ENG. ASCE, V. 125, No. 2, 1999, pp. 126-140.

[11] Lee, D., and Chiu, J. J. "Computation of Physiological Bifurcation Flows Using a Patched Grid", Comput. Fluids, V. 21, No. 4, 1992, pp. 519-535.

[12] Hsu, Chung-Chieh, Tang. Chii, Jau, Lee, Wen-Jung and Shieh, Mon-Yi. (2002). "Subcritical 90 equal-width open-channel dividing flow.” ASCE J. HYDRAUL. ENG.. Vol. 128, No. 7, PP. 716-720.

[13] Song, T., and Graf, W. H. 1998. Velocity and Turbulence
Distribution in unsteady Open channel Flows. J. Hr. Eng. Vol. 122, No. 3.

[14] Reid, Ian, Laronne, Jonathan. b., and Powell, Mark.1998. Prediction of Bed-Load Transport by Desert Flash Floods. J. of hyd. Eng. vol., 122, No. 3.

[15] Rankl, j. G. 1987. Analysis of sediment production form two small semiarid basins in Wyoming: U.s. Geological Survey Water Resources Investigation Report 85-4314,27p.

[16] Graf, W. H., and Suszka, L. 1985. Unsteady Flow and its Effect on Sediment Transport. $21^{\text {st }}$ IAHR congress Melbourne.

[17] Duan J. G., He L., Fu X., and Wang Q., (2009). Mean flow and turbulence around experimental spur dike. Advances in Water Resources, Vol. 32, No. 22, pp. 1717-1725.

[18] Vaghefi M., Ghodsian M. and Salehi Neyshabori S. A. A., (2012). Experimental Study on Scour around a T-Shaped Spur Dike in a Channel Bend. Journal of Hydraulic Engineering, Vol. 138. 